\title{
Impairment of microcirculation and energy metabolism in intermittent claudication: beneficial effects of exercise training
}

\author{
Miglioramento del microcircolo e del metabolismo energetico \\ nella claudicatio intermittens: effetti favorevoli del training fisico
}

\author{
Eugenio Laurenzano, Lucrezia Spadera, Mario De Laurentis, Gregorio Brevetti
}

\begin{abstract}
Impairment of microcirculation and energy metabolism in intermittent claudication: beneficial effects of exercise training. E. Laurenzano, L. Spadera, M. De Laurentis, G. Brevetti.

Although in peripheral arterial disease (PAD) the primary determinant of inadequate blood supply to the affected limb during exercise is a flow-limiting lesion of a conduit artery, there is a large body of evidence that impairment of microcirculation and skeletal muscle energy metabolism play a relevant role in the reduced working ability of affected individuals. This review was conceived to cast some light on this topic, paying special attention to the functional benefits of exercise training (ET) in the treatment of claudicant patients.

In PAD, the ischemia induced by maximal exercise increases oxidative stress, inflammation and endothelial dysfunction. Perturbation of the endothelial homeostasis results
\end{abstract}

in increased adhesiveness of leukocytes and platelets, and in reduced vasodilator capability. These events, expression of the interplay between inflammation and endothelium, provoke an obstacle in the microcirculation with a reduction in the nutritive blood flow, leading to acidosis and impaired energy metabolism in skeletal muscle, with consequent reduced exercise tolerance.

ET counteracts these effects by improving walking ability and quality of life in patients with intermittent claudication, thus representing the gold standard in the treatment of PAD.

Keywords: peripheral arterial disease, intermittent claudication, microcirculation, skeletal muscle energy metabolism, exercise training.

Monaldi Arch Chest Dis 2009; 72: 110-117.

Department of Clinical Medicine and Cardiovascular and Immunological Sciences, University of Naples "Federico II".

Corresponding author: Eugenio Laurenzano MD; P.zza Tempio Mag.re 6 - I-83042 Atripalda (AV), Italy; Tel./Fax: +39 081 7462240; E-mail address: eugeniolaurenzano82@katamail.com

\section{Introduction}

Peripheral arterial disease (PAD), presenting as intermittent claudication (IC), affects a large proportion of the general population $[1,2]$ and is one of the major causes of disability in middle age and elderly $[3,4]$. Despite its relevance, PAD treatment still remains a challenge. This is essentially due to the fact that, for a long time, the pathophysiology of this condition remained unknown, and the narrowing of a proximal artery was considered the only factor responsible for the reduced oxygenation in the skeletal muscle. Conversely, the restriction of blood flow in a proximal artery is only the primum movens of a sequence of microcirculatory alterations accounting for the mismatch between metabolic supply and demand in the affected skeletal muscle.

In IC patients with, nutritive capillary flow is not compromised at rest [5] and the muscle metabolic state is only slightly impaired $[6,7]$. In these patients, however, exercise causes a reduction in blood flow [8], probably as a result of blood diversion from the ischemic area [9]. This acute reduction in the perfusion pressure induces a markedly inflammatory response and perturbation of endothelial function that cause a profound disruption in microcirculatory homeostasis and skeletal muscle energy metabolism.

\section{Microcirculation}

Microcirculation comprises the arterioles, capillaries, venules, initial lymphatic vessels and, in a more wide sense, the endothelium that covers these vascular structures and the circulating cells. It may be considered as a system where each component also interacting with the others, contributes to maintain circulatory, coagulative and metabolic homeostasis. Under normal perfusion condition, endothelial cells are in the non-activated state and have a normal morphology. Erythrocytes, and also leukocytes and platelets are in non-secretory, non-adherent state and thus there is no obstacle to the blood flow that provides oxygen and substrates for energy production at a rate commensurate to the metabolic requirements of the skeletal muscle.

\section{Effect of ischemia on endothelium}

Maximal exercise-induced ischemia in PAD evokes a systemic response characterized by increased oxidative stress, inflammation and endothe- 
lial dysfunction [10-15]. In particular, in affected individuals exercise induces increase in plasma levels of thiobarbituric acid-reactive substances [16], accompanied by an increase in thromboxane and interleukin-8 [10,11, 17], and elevated plasma levels of intercellular adhesion molecules-1 (sICAM-1), vascular cell adhesion molecules (sVCAM-1), vonWillebrand factor (vWF), E-selectin, endothelin-1 (ET-1), thrombomodulin, and circulating endothelial progenitor cells EPCs. [18-25]. Furthermore, a maximal working load induces depressed artery brachial flow-mediated endothelial-dependent dilation (FMD, an index of endothelial dysfunction).

In addition to the above described systemic inflammatory response, and probably even more important with respect to the impairment of microvascular circulation in the affected limb, acute exercise incites a local inflammatory response. In 17 patients with one-sided PAD, Neumann et al. [26], found that immediately after claudication, total neutrophil number, neutrophil flexibility and the proportion of activated neutrophil were increased in the venous draining from the affected leg versus the arterial blood. These venous-arterial differences were not observed in the circulation of the exercising contralateral healthy leg. The aforementioned alterations, typically inflammatory in nature, may act so that a certain number of neutrophils remains entrapped in the microcirculation of the affected limb causing vessel plugging. Furthermore activated leukocytes release thromboxane A2, which in addition to be a vasoconstrictor, promotes platelet aggregation [27], so inducing the phenomenon of platelet plugging. To this phenomenon in claudicants may also participate overexpression of P-selectin $[28,29]$ which mediates platelet-endothelium interaction [30]. Consistent with the observation by Neumann et al. [26], our group observed that in the claudicant limb, but not in the healthy legs of the control group, maximal exercise increased the transfemoral venous-arterial difference of the neutrophil myeloperoxidase (MPOx) content [31], an index of neutrophil activation and a well established marker of inflammation [32]. MPOx is an enzyme which, when released by activated neutrophils, exerts very harmful effects on the endothelium [32]. In particular, it uses nitric oxide (NO) as a physiologic substrate, thereby reducing the bioavailability of this gas which is fundamental for the endothelial homeostasis. In addition to MPOx, activated neutrophils release various noxious substances, among which elastase, that has been shown to have harmful effects for the endothelium in vitro [33], and show a progressive increase from normal, asymptomatic PAD patients, to claudicants [34]. Furthermore, in claudicants, its levels have been shown to further increase with exercise [35]. Disturbed endothelium results in a reduced vasodilator capability and in the already mentioned increased adhesiveness to leukocytes and platelets which causes a physical obstruction to microcirculation. An additional mechanism that may favour the adherence of neutrophil to endothelium is impaired shear stress, which also involves an inflammatory reaction. Indeed, the CD11b/CD18ICAM-1 adhesion mechanism is very sensitive to shear stress as low as 0.5 dyne/sec [36]. Obviously, distal to an obstruction there is considerable turbulence so that there is a strong likelihood of a low shear stress zone distally to the obstruction. Finally, endothelial cell swelling, favoured by acidosis [37], may cause a further obstacle to microcirculation [38, 39]. All these events, expression of the interaction between inflammation and endothelium, by reducing the nutritive blood flow, leads to acidosis and impaired energy metabolism with consequent reduced exercise tolerance (Fig. 1).

\section{Oxygen delivery to the tissue}

One of the most important functions of the blood circulation is oxygen delivery to the tissues. The classical scheme of tissue oxygenation assumes that oxygen passes to the tissue via the capillaries. However, blood entering capillaries is only $50 \%$ saturated [40], thus implying that half of $\mathrm{O}_{2}$ gathered by the lungs exits the circulation prior to arriving to the capillaries include oxygen shunting from arterioles to parallel venules, arteriolar-capillary oxygen diffusional shunting and periarteriolar tissue consumption.

\subsection{Arterioles and tissue oxygenation}

The first demonstration that capillaries are not the sole source of oxygen for the tissues dates back to 1970 when Duling and Berne found that significant amounts of oxygen exit the arteriolar network [40]. More recently, the phosphorescence decay technology [41] provides means for evaluating simultaneously intra- and extravascular $\mathrm{pO}_{2}$, and therefore it is a direct method of evaluating both longitudinal vessel $\mathrm{pO}_{2}$ gradients (or blood oxygen saturation gradients) and the perivascular $\mathrm{pO}_{2}$ tissue gradients that presumably determinate the rate of oxygen exit from blood vessels. Results confirm that a major portion of blood oxygen is delivered to the tissue by the arterioles. Furthermore, this technique allows an accurate mass balance between the decrease of oxygen content in the arterioles and the diffusion flux of oxygen out the microvessels are determined by the oxygen gradient measured in the surrounding tissue. These measurements support the hypothesis that the exit of oxygen from arterioles is due to a high rate if oxygen utilization by the vascular wall.

\subsection{The arteriolar wall as an oxygen sink}

When endothelium is removed from the dog hind limb, oxygen consumption decreases by $34 \%$ [42]. Indeed, endothelium is capable of metabolic activity which can be 100-fold that of other cells [43]. It is the site of chemical synthesis and metabolic processes that require oxygen. These include synthesis and secretion of renin, prostaglandins, collagen, NO, endothelin, prostacyclin, interleukin, degradation of bradykinin and prostaglandins, clearance of proteins, lipids and lipoproteins, expression of adhesion molecules. Moreover, endothelial cells have an active actin/myosin-based contractile system that also may consume $\mathrm{O}_{2}$ [44]. Therefore, it is conceivable that during the metabolic stress induced by ischemia more oxygen is consumed by the endothelium and less becomes available to the metabolic requirements of the muscle. This pathophysio- 


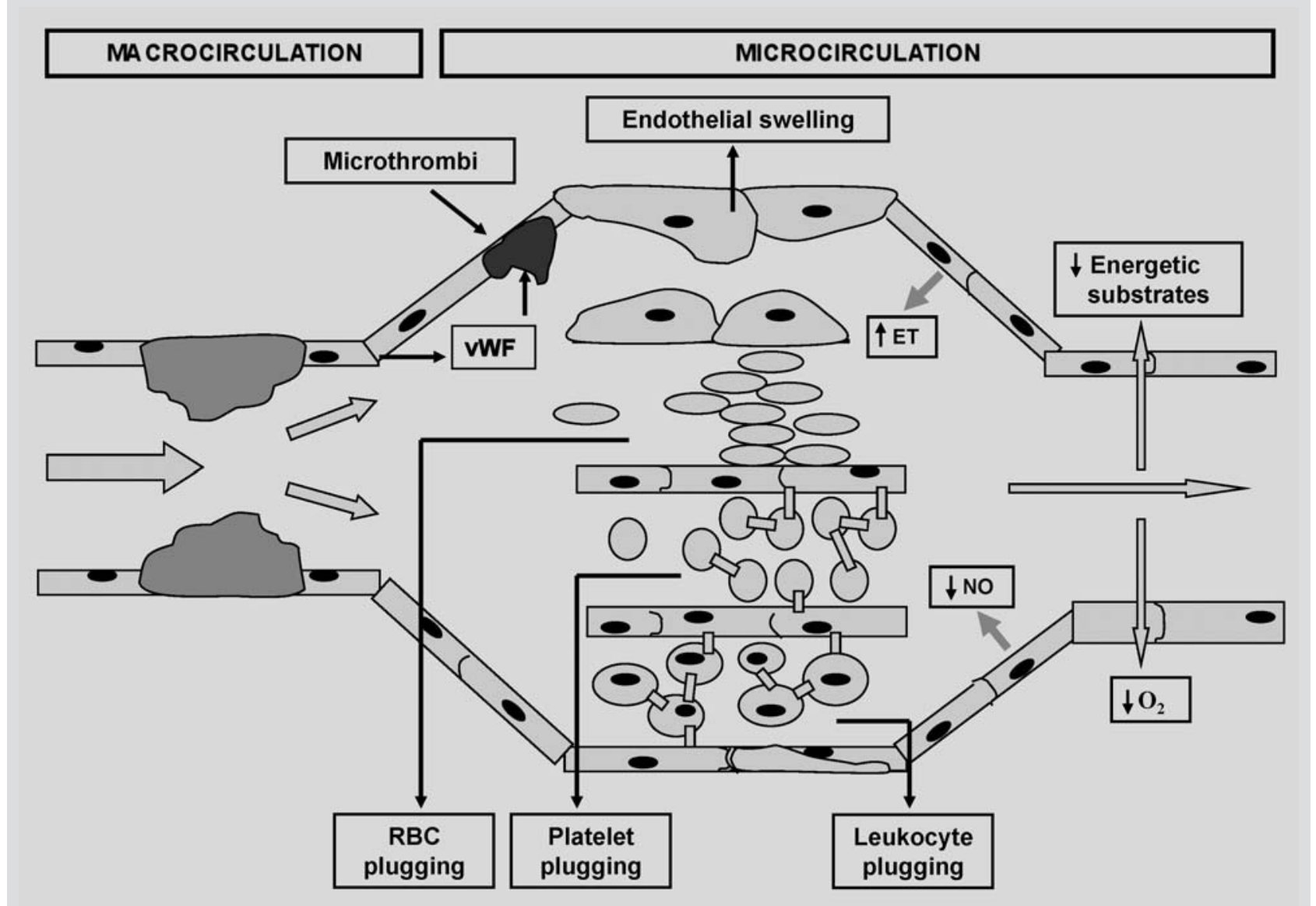

Figure 1. - Some possible causes of microvascular flow impairment in intermittent claudication.

logic mechanism could contribute to the alteration of oxidative machinery occurring in the skeletal muscle during claudication.

\section{Skeletal muscle metabolism}

Mitochondrial Adenosine TriPhosphate (ATP) regeneration is the principal mechanism in the skeletal muscle for meeting energy requirements for sustained force production. It depends on the activity of tricarboxylic acid (TCA) cycle that is fuelled by acetyl-CoA formed primarily from oxidation of pyruvate and fatty acids. The rate of these metabolic pathways is coupled to the rate of muscle work, and conversely, muscle work is coupled to the supply of oxygen and the rate of oxidative phosphorylation. At low work loads (defined as those below the lactate threshold), muscle metabolism is primarily aerobic, with fatty acids as the primary substrate [45]. Conversely, at high work loads (above the lactate threshold), carbohydrates serve as the primary substrate for exercising muscle [46], and thus acetyl-CoA is formed from pyruvate through the action of pyruvate dehydrogenase (PDH). However, with high intensity exercise, the rate of acetyl-CoA formation exceeds the maximal capacity of the TCA. As a consequence, acetyl-CoA tends to accumulate within the mitochondria, increasing the acetyl-CoA/CoA ratio and thus inhibiting PDH. The reduced oxidative utilization of glucose leads to increased lactate formation. Under these conditions the role of carnitine is crucial. It serves as a "buffer" of the metabolically critical mitochondrial acetylCoA pool [47]. Through the action of carnitine acetyl transferase, carnitine depletes acetyl-CoA and releases free CoA and acetyl-carnitine, which, unlike acetyl-CoA, may be transported out of the mitochondria and released in the blood stream (Fig. 2). Indeed, increased levels of acetylcarnitine occur in muscle and plasma of normal subjects performing maximal exercise [32].

\subsection{Effect of ischemia}

Muscle ischemia adversely affects muscle metabolism. In the ischemic muscle during exercise the levels of inorganic phosphate are very high as the breakdown of ATP and phosphocreatine is elevated. Therefore, the ratio of inorganic phosphates to phosphocreatine increases to a greater extent than in normoperfused muscle. The result is a higher rate of glycolytic metabolism as indicated by the marked drop in pH (Fig. 3) These changes observed by 31P magnetic resonance spectroscopy [7] are in accordance with biopsy studies, which demonstrated increased accumulation of lactate and depletion of cellular ATP during exercise in claudicants compared to normal subject [8]. Reduced ATP synthesis results from the reduced vascular perfusion which decreases both oxygen delivery (thus impairing mitochondrial oxidation) and the washout of toxic metabolites from the muscle (hence inhibiting many enzymatic activities and cellular proton efflux). In particular, patients with claudication accumulate acetylcarnitine (thus reflecting acetyl-CoA accumulation) and lactate (as a consequence of PDH inhibition). Importantly, there is an inverse correlation between both plasma and muscle levels of acetylcarni- 


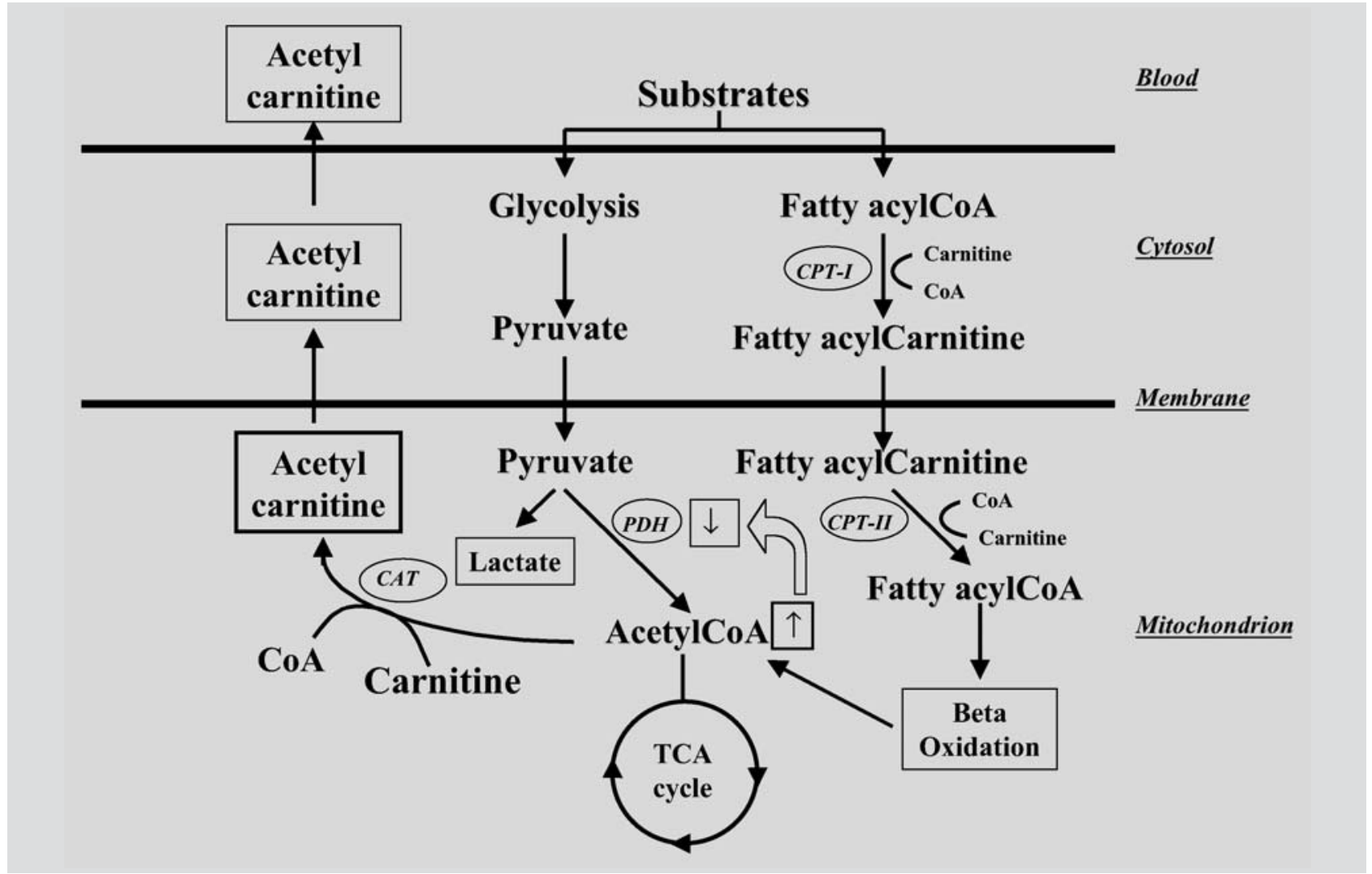

Figure 2. - Schematic depiction of skeletal muscle substrate metabolism. Note that accumulation ( $\uparrow$ ) of acetyl-CoA within the mitochondria inhibits $(\downarrow)$ the activity of PDH. Carnitine removes the acetyl-CoA excess by forming acetylcarnitine. PDH= pyruvate dehydrogenase; CPT= carnitine palmitoyl transferase; $\mathrm{CAT}=$ carnitine acetyl transferase.

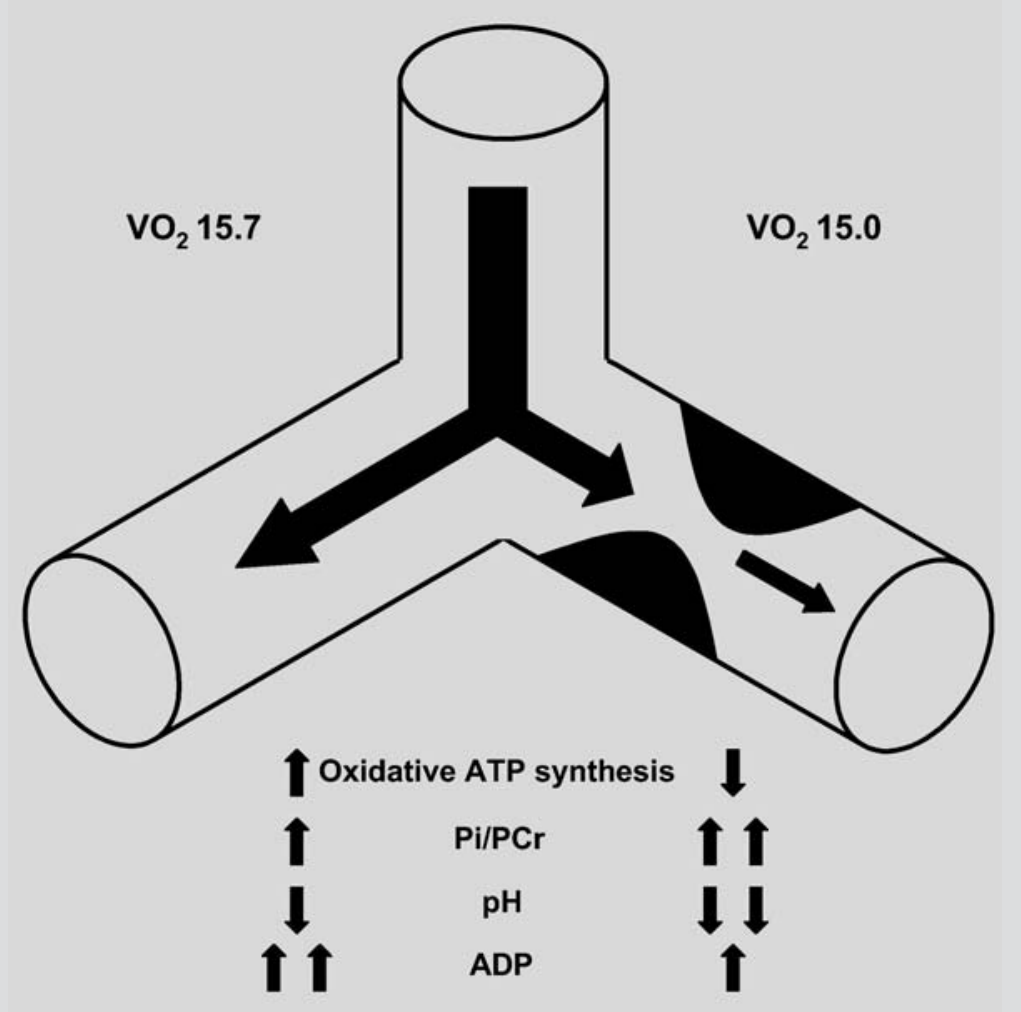

Figure 3. - 31P MRS data in exercising muscle of normal subjects and patients with peripheral ischemia (note that in the normoperfused muscle, in the early phase of the exercise there is a slight increase in the oxidative ATP synthesis). In the ischemic muscle during exercise the levels of inorganic phosphate are very high as the breakdown of ATP and phosphocreatine is elevated. Therefore, the ratio of inorganic phosphates to phosphocreatine increases to a greater extent than in normoperfused muscle. The result is a higher rate of glycolytic metabolism as indicated by the marked drop in $\mathrm{pH}$. ATP= adenosine triphosphate; $\mathrm{Pi}=$ inorganic phosphate; $\mathrm{PCr}=$ phosphocreatine; $\mathrm{ADP}=$ adenosine diphosphate; $\mathrm{VO}_{2}=$ oxygen comsuption. tine and subsequent assessments of peak exercise performance suggesting that in patients with IC, altered carnitine metabolism might be associated with the altered muscle energy metabolism $[6,49]$. Patients with mild functional impairment have low resting plasma levels of acetylcarnitine that normally increase with exercise, while the most affected patients have elevated resting levels of acetylcarnitine and do not form these esters with exercise [50]. Plasma concentration of acetylcarnitine depends, at least in part, on two factors, the rate of formation of acetyl-CoA and the availability of carnitine to remove if from mitochondria. Thus, it is conceivable that in patients with moderate to severe claudication, the overutilization of carnitine at rest (as reflect by the elevated levels of acetylcarnitine) results in a condition of carnitine insufficiency, i.e. insufficient availability of carnitine to meet the increased metabolic demand induced by walking. Indeed, such patients after carnitine supplementation showed with exercise an increase in plasma acetylcarnitine as opposed to 
the decrease observed before treatment [50]. This implies that a corresponding amount of acetyl-CoA was removed from mitochondria with consequent stimulation of PDH. Indeed, in patients with IC, carnitine administration results in a reduction of the lactate concentration in the venous blood leaving the exercising ischemic muscle [51].

\section{Benefits of exercise training (ET) in PAD}

In 1957, Foley [52] described the beneficial effects of daily walks and physical training in patients with IC. Several subsequent reports confirmed these findings, and in particular, a meta-analysis from the Cochrane Collaboration [53], concluded that exercise improves maximal working time by an average of $150 \%$, an extent that would appear to exceed that obtained with current pharmacological therapies.

Although the mechanisms by which ET yields improvements in walking ability remain speculative, many changes that occur during supervised physical activity presumably simulate an adaptative response that ultimately reduces claudication symptoms [54]. One of the mechanisms may be the increase in blood flow consequent to the process of collateralization. This is traditionally viewed as a recruitment of pre-existing collaterals (arteriogenesis) or an expansion of microvessels (angiogenesis) into ischemic areas. Following a program of ET, humans with heart failure will increase expression of vascular endothelial growth factor (VEGF) messenger RNA in skeletal muscle [55], and animal models of limb ischemia reveal an increase in collateral development [56, 57]. However, in humans, studies demonstrating collateral development or increase in calf blood flow in response to ET are limited and conflicting [58-63]. In PAD, Gardner et al. [61] showed that six months of exercise increased maximal calf blood flow by $30 \%$, and this change was associated with improved walking ability $(\mathrm{r}=0.38$, $\mathrm{P}<0.05)$. On the other hand, a number of other studies did not document increased leg blood flow in patients with IC, although all of them reported an improvement in exercise performance [58-61]. Hence, other mechanisms must account for the large exercise-induced improvements in function and symptoms that occur in patients with claudication.

While acute exercise incites a systemic and local inflammatory response, ET reduces free radical damage, neutrophil activation, plasma levels of plasma markers such as C-Reactive Pro- tein (CRP), Serum Amyloid A (SAA), CD11b [64], and increases endothelial NO synthase (eNOS) expression and phosphorylation [65]. The consequence of these changes is an increased activity of $\mathrm{NO}$, the synthesis of which is reduced in claudicant patients [66]. In animal models of peripheral ischemia, ET improves NO activity [66], and thus it is presumably that it counteracts the microcirculatory alteration described above. Unfortunately, studies of ET on vasodilator endothelial function in patients with claudication are limited. An uncontrolled study [67] found that training induced-improvements in walking ability was associated with an increase in FMD. Furthermore, in 22 PAD patients Andreozzi et al. [17] measured baseline and post-exercise FMD, before and after ET. Before training the pre-exercise FMD was $7.6 \pm 2.9$ and post-exercise $5.3 \pm 3.3$ $(-33.2 \%)(\mathrm{P}<0.01)$. After training the pre-exercise FMD was $10.3 \pm 4.04$ and post-exercise $7.8 \pm 2.6$ $(-18.97 \%)(\mathrm{P}<0.01)$. Thus, ET increased both baseline and post-exercise FMD. Furthermore, it halved the difference in FMD between the pre- and post-exercise observed before and after training, although this was not statistical significant.

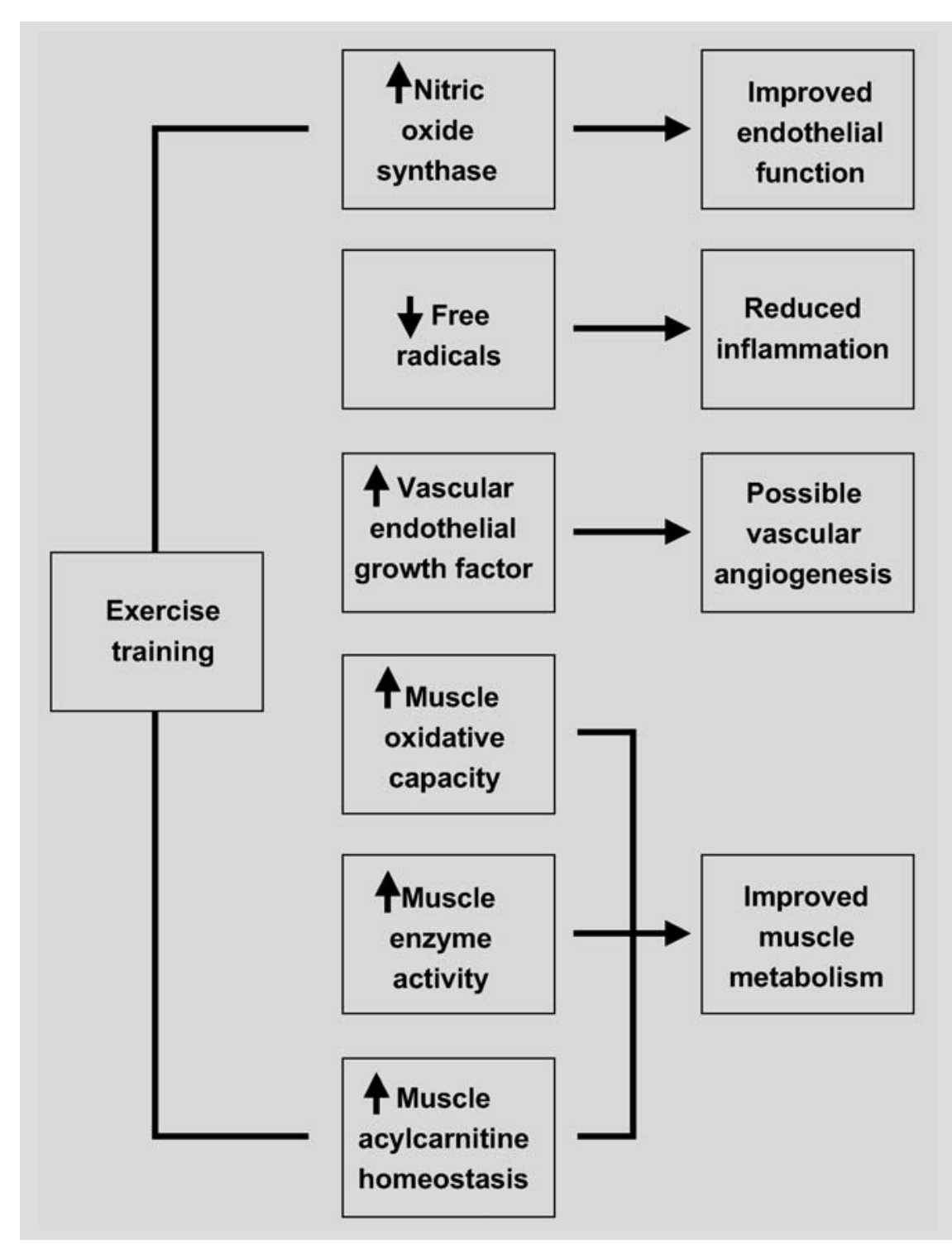

Figure 4. - Schematic overview of the potential favourable effects of ET in PAD. ET= exercise training; $\mathrm{PAD}=$ peripheral arterial disease (modified from Stewart et al. [71]). 
Finally, ET induces multiple beneficial effects in the structure and metabolism of skeletal muscle. It increases the percentage of oxidative type 1 fibers and decreases the density of type $2 \mathrm{~B}$ glycolytic fibers. Furthermore, it increases the volume density of mitochondria [68]. In a phosphorus-31 nuclear magnetic resonance spectroscopy study, after physical training, the phosphocreatine depletion and the increase in adenosine diphosphate (ADP) during exercise were reduced significantly although there were no significant changes in the response of muscle $\mathrm{pH}$ to exercise. The substantial correction of the impaired oxidative metabolism of skeletal muscle was confirmed by the finding that in untrained subjects the initial rate of phosphocreatine resynthesis after exercise (a measure of the rate of oxidative ATP synthesis and the inferred maximal rate of mitochondrial ATP synthesis were reduced compared with rates in control subjects $(\mathrm{P}<0.003)$ and both were significantly increased $(\mathrm{P}<0.05)$ by training [69].

To the best of our knowledge, only one study investigated the effects of ET on skeletal muscle histology and metabolism in PAD. Hiatt et al. [70] performed gastrocnemius muscle biopsies at rest and before and after ET. At 12 weeks training did not alter type 1 or type 2 fiber areas and did not increase citrate synthase activity. Improvements in exercise performance with training were associated with a correlative decrease in plasma ( $\mathrm{r}=-$ $0.067)$ and muscle $(r=-0.59)$ short chain acylcarnitine concentration. As reported above, such a decrease of resting plasma levels of short-chain acylcarnitine implies a greater availability of carnitine with consequent amelioration of energy metabolism [70].

\section{Conclusions}

Although the pathophysiology of IC is primarily accounted for a flow-limiting stenosis of a conduct artery, a large body of evidence indicates that impairments in microcirculation and energy metabolism play a relevant role in the reduced working ability of affected individuals. In microvessels, disturbed endothelium results in increased adhesiveness of leukocytes and platelets which causes physical obstruction. The consequent reduction in nutritive blood flow leads to acidosis and impaired energy metabolism with secondary decrease in exercise tolerance. By counteracting these effects, ET is considered by the American Heart Association the treatment of choice for improving walking ability and quality of life in IC patients [71].

\section{Riassunto}

Sebbene nell'arteriopatia obliterante degli arti inferiori (AOAI) la causa principale dell'inadeguato apporto di sangue all'arto affetto durante l'esercizio fisico $(E F)$ sia una stenosi in un condotto arterioso, molte evidenze indicano che alterazioni del microcircolo e del metabolismo energetico del muscolo scheletrico giocano un ruolo rilevante nella ridotta autonomia funzionale dei pazienti con claudicatio intermittens $(\mathrm{CI})$.
Lo scopo di questa rassegna è stato quello di far luce su questo argomento, ponendo maggiore attenzione sui benefici derivanti dall'EF nel trattamento dei pazienti arteriopatici.

Nell'AOAI, l'ischemia derivante dall'esercizio massimale aumenta lo stress ossidativo, l'infiammazione e la disfunzione endoteliale. L'alterazione dell'omeostasi endoteliale comporta un'aumentata adesività leucocitaria e piastrinica, ed una ridotta capacità vasodilatatoria. Questi eventi, espressione dell'interazione tra infiammazione ed endotelio, ostacolano l'apporto di sostanze nutritive al microcircolo. Tutto ciò può causare acidosi ed alterazioni nel metabolismo energetico del muscolo scheletrico, con conseguente riduzione dell'autonomia funzionale.

$L^{\prime} E F$, neutralizzando questi effetti, migliora l'autonomia di marcia e la qualità della vita nei pazienti con CI, rappresentando così il gold standard nel trattamento dell'AOAI.

Parole chiave: arteriopatia obliterante degli arti inferiori, claudicatio intermittens, microcircolo, metabolismo energetico del muscolo scheletrico, esercizio fisico.

\section{ABBREVIATION LIST}

PAD: Peripheral Arterial Disease

IC: Intermittent Claudication

FMD: Flow-Mediated Dilation

MPOx: Myeloperoxidase

NO: Nitric Oxide

ATP: Adenosine TriPhosphate

TCA: TriCarboxylic Acid

PDH: Pyruvate dehydrogenase

ET: Exercise Training

\section{References}

1. Kannelland WB, Mc Gee DL. Updateon some epidemiologic features of intermittent claudication: the Framingham study. J Am Geriatr Soc 1985; 33: 13-8.

2. Mc Daniel MD, Cronewett JL. Basic data related to the natural history of intermittent claudication. Ann Vasc Surg 1989; 3: 273-7.

3. Arfvidsson B, Karlsson J, Dahllöf AG, Lundholm K, Sullivan $\mathrm{M}$. The impact of intermittent claudication on quality of life evaluated by the Sickness Impact Profile technique. Eur J Clin Invest 1993; 23: 741-5.

4. Barletta G, Perna S, Sabba C, Catalano A, O'Boyle C, Brevetti G. Quality of life in patients with intermittent claudication: relationship with laboratory exercise performance. Vasc Med 1996; 1: 3-7.

5. Schellong SM, Böger RH, Burchert W, et al. Dose-related effect of intravenous L-arginine on muscular blood flow of the calf in patients with peripheral vascular disease: a $\mathrm{H} 215 \mathrm{O}$ positron emission tomography study. Clin Sci (Lond) 1997; 93: 159-65.

6. Hiatt WR, Wolfel EE, Regensteiner JG, Brass EP. Skeletal muscle carnitine metabolism in patients with unilateral peripheral arterial disease. J Appl Physiol 1992; 73: 346-53

7. Kemp GJ, Hands LJ, Ramaswami G, et al. Calf muscle mitochondrial and glycogenolytic ATP synthesis in patients with claudication due to peripheral vascular disease analysed using 31P magnetic resonance spectroscopy. Clin Sci (Lond) 1995; 89: 581-90.

8. Pernow B, Saltin B, Wahren J, Cronestrand R, Ekestroöm $\mathrm{S}$. Leg blood flow and muscle metabolism in occlusive arterial disease of the leg before and after reconstructive surgery. Clin Sci Mol Med 1975; 49: 265-75. 
9. Brevetti G, Chiariello M, Rengo F, Lavecchia G, Paudice G, Condorelli M. Protective effects of propranolol on the exercise-induced reduction of blood flow in arteriopathic patients. Angiology 1979; 30: 696-702.

10. Eberhardt RT, Coffman JD. Cardiovascular morbidity and mortality in peripheral arterial disease. Curr Drug Targets Cardiovasc Haematol Disord 2004; 4: 209-17.

11. Edwards AT, Blann AD, Suarez-Mendez VJ, Lardi AM, McCollum CN. Systemic responses in patients with intermittent claudication after treadmill exercise. Br J Surg 1994; 81: 1738-41.

12. Belch JJF, McLaren M, Khan F, Hickman P, Stonebridge $\mathrm{M}$, Stonebridge P. The inflammatory process in intermittent claudication. Eur Heart J Suppl 2002; 4: B35-40.

13. Silvestro A, Scopacasa F, Oliva G, de Cristofaro T, Iuliano L, Brevetti G. Vitamin C prevents endothelial dysfunction induced by acute exercise in patients with intermittent claudication. Atherosclerosis 2002; 165: 277-83.

14. Kirk G, Hickman P, McLaren M, Stonebridge PA, Belch JJ. Interleukin-8 (IL-8) may contribute to the activation of neutrophils in patients with peripheral arterial occlusive disease (PAOD). Eur J Vasc Endovasc Surg 1999; 18: 434-8.

15. Brevetti G, Corrado S, Martone VD, Di Donato A, Silvestro A, Vanni L. Microcirculation and tissue metabolism in peripheral arterial disease. Clin Hemorheol Microcirc 1999; 21: 245-54.

16. Belch JJ, Mackay IR, Hill A, Jennings P, McCollum P. Oxidative stress is present in atherosclerotic peripheral arterial disease and further increased by diabetes mellitus. Int Angiol 1995; 14: 385-8.

17. Andreozzi GM, Martini R, Cordova R, et al. Circulating levels of cytokines (IL-6 and IL-1beta) in patients with intermittent claudication, at rest, after maximal exercise treadmill test and during restore phase. Could they be progression markers of the disease. Int Angiol 2007; 26: 245-52.

18. Hiatt WR. Medical treatment of peripheral arterial disease and claudication. $N$ Engl J Med 2001; 344: 1608-21.

19. Blann AD, Dobrotova M, Kubisz P, McCollum CN. von Willebrand factor, soluble P selectin, tissue plasminogen activator and plasminogen activator inhibitor in atherosclerosis. Thromb Haemost 1995; 74: 626-30.

20. Brevetti G, De Caterina M, Martone VD, et al. Exercise increases soluble adhesion molecules ICAM-1 and VCAM-1 in patients with intermittent claudication. Clin Hemorheol Microcirc 2001; 24: 193-9.

21. Signorelli SS, Mazzarino MC, Di Pino L, et al. High circulating levels of cytokines (IL-6 and TNFalpha), adhesion molecules (VCAM-1 and ICAM-1) and selectins in patients with peripheral arterial disease at rest and after a treadmill test. Vasc Med 2003; 8: 15-9.

22. Mangiafico RA, Malatino LS, Spada RS, et al. Treadmill exercise induced release of endothelin-1 in patients with peripheral arterial occlusive disease at Fontaine stage IIb. Int Angiol 2000; 19: 14-7.

23. Brevetti G, Schiano V, Chiariello M. Endothelial dysfunction: a key to the pathophysiology and natural history of peripheral arterial disease? Atherosclerosis 2008; 197: $1-11$.

24. Laufs U, Werner N, Link A et al. Physical training increases endothelial progenitor cells, inhibits neointima formation, and enhances angiogenesis. Circulation 2004; 109: 220-26.

25. Rehman J, Li J, Parvathaneni L et al. Exercise acutely increases circulating endothelial progenitor cells and monocyte-macrophage-derived angiogenic cells. J Am Coll Cardiol 2004; 43: 2314-18.

26. Neumann FJ, Waas W, Diehm C, et al. Activation and decreased deformability of neutrophils after intermittent claudication. Circulation 1990; 82: 922-9.

27. Paul BZ, Jin J, Kunapuli SP. Molecular mechanism of thromboxane A(2)-induced platelet aggregation. Essential role for $\mathrm{p} 2 \mathrm{t}(\mathrm{ac})$ and alpha(2a) receptors. J Biol Chem 1999; 274: 29108-14.
28. Kirkpatrick UJ, Mossa M, Blann AD, McCollum CN. Repeated exercise induces release of soluble P-selectin in patients with intermittent claudication. Thromb Haemost 1997; 78: 1338-42.

29. Cassar K, Bachoo P, Ford I, Greaves M, Brittenden J. Platelet activation is increased in peripheral arterial disease. J Vasc Surg 2003; 38: 99-103.

30. Hope SA, Meredith IT. Cellular adhesion molecules and cardiovascular disease. Part I. Their expression and role in atherogenesis. Intern Med J 2003; 33: 380-6.

31. Brevetti G, Piscione F, Cirillo P, et al. In concomitant coronary and peripheral arterial disease, inflammation of the affected limbs predicts coronary artery endothelial dysfunction. Atherosclerosis 2008; 201: 440-6.

32. Nicholls SJ, Hazen SL. Myeloperoxidase and cardiovascular disease. Arterioscler Thromb Vasc Biol 2005; 25: 1102-11.

33. Mehta J, Dinerman J, Mehta P, et al. Neutrophil function in ischemic heart disease. Circulation 1989; 79: 549-56.

34. Lowe GD, Fowkes FG, Dawes J, Donnan PT, Lennie SE, Housley E. Blood viscosity, fibrinogen, and activation of coagulation and leukocytes in peripheral arterial disease and the normal population in the Edinburgh Artery Study. Circulation 1993; 87: 1915-20.

35. Turton EP, Coughlin PA, Kester RC, Scott DJ. Exercise training reduces the acute inflammatory response associated with claudication. Eur J Vasc Endovasc Surg 2002; 23: 309-16.

36. Kloner RA, Giacomelli F, Alker KJ, Hale SL, Matthews $\mathrm{R}$, Bellows S. Influx of neutrophils into the walls of large epicardial coronary arteries in response to ischemia/reperfusion. Circulation 1991; 84: 1758-72.

37. Behmanesh S, Kempski O. Mechanisms of endothelial cell swelling from lactacidosis studied in vitro. Am J Physiol Heart Circ Physiol 2000; 279: H1512-7.

38. Hickey NC, Hudlicka O, Gosling P, Shearman CP, Simms MH. Intermittent claudication incites systemic neutrophil activation and increased vascular permeability. Br J Surg 1993; 80: 181-4.

39. Thomson IA, Egginton S, Simms MH, Hudlická O. Effect of muscle ischaemia and iloprost during femorodistal reconstruction on capillary endothelial swelling. Int $J \mathrm{Mi}$ crocirc Clin Exp 1996; 16: 284-90.

40. Duling BR, Berne RM. Longitudinal gradients in periarteriolar oxygen tension. A possible mechanism for the participation of oxygen in local regulation of blood flow. Circ Res 1970; 27: 669-78.

41. Intaglietta M, Johnson PC, Winslow RM. Microvascular and tissue oxygen distribution. Cardiovasc Res 1996; 32: 632-43.

42. Curtis SE, Vallet B, Winn MJ, et al. Role of the vascular endothelium in $\mathrm{O} 2$ extraction during progressive ischemia in canine skeletal muscle. J Appl Physiol 1995; 79: 1351-60.

43. Bruttig SP, Joyner WL. Metabolic characteristics of cells cultured from human umbilical blood vessels: comparison with 3T3 fibroblasts. J Cell Physiol 1983; 116: $173-80$

44. Boswell CA, Majno G, Joris I, Ostrom KA. Acute endothelial cell contraction in vitro: a comparison with vascular smooth muscle cells and fibroblasts. Microvasc Res 1992; 43: 178-91.

45. Jones NL, Heigenhauser GJ, Kuksis A, Matsos CG, Sutton JR, Toews CJ. Fat metabolism in heavy exercise. Clin Sci (Lond) 1980; 59: 469-78.

46. Pirnay F, Crielaard JM, Pallikarakis N, et al. Fate of exogenous glucose during exercise of different intensities in humans. J Appl Physiol 1982; 53: 1620-4.

47. Cerretelli P, Marconi C. L-carnitine supplementation in humans. The effects on physical performance. Int $J$ Sports Med 1990; 11: 1-14.

48. Hiatt WR, Regensteiner JG, Wolfel EE, Ruff L, Brass EP. Carnitine and acylcarnitine metabolism during exercise in 
humans. Dependence on skeletal muscle metabolic state. J Clin Invest 1989; 84: 1167-73.

49. Hiatt WR, Nawaz D, Brass EP. Carnitine metabolism during exercise in patients with peripheral vascular disease. $J$ Appl Physiol 1987; 62: 2383-7.

50. Brevetti G, di Lisa F, Perna S, et al.Carnitine-related alterations in patients with intermittent claudication: indication for a focused carnitine therapy. Circulation 1996; 93: $1685-9$.

51. Brevetti G, Chiariello M, Ferulano G, et al. Increases in walking distance in patients with peripheral vascular disease treated with L-carnitine: a double-blind, cross-over study. Circulation 1988; 77: 767-73.

52. Foley WT. Treatment of gangrene of the feet and legs by walking. Circulation 1957; 15: 689-700.

53. Ashworth NL, Chad KE, Harrison EL, Reeder BA, Marshall SC. Home versus center based physical activity programs in older adults. Cochrane Database Syst Rev 2005; 25: CD004017.

54. Fukai T, Siegfried MR, Ushio-Fukai M, Cheng Y, Kojda G, Harrison DG. Regulation of the vascular extracellular superoxide dismutase by nitric oxide and exercise training. J Clin Invest 2000; 105: 1631-9.

55. Gustafsson T, Bodin K, Sylvén C, Gordon A, Tyni-Lenné $\mathrm{R}$, Jansson E. Increased expression of VEGF following exercise training in patients with heart failure. Eur J Clin Invest 2001; 31: 362-6.

56. Mathien GM, Terjung RL. Muscle blood flow in trained rats with peripheral arterial insufficiency. Am J Physiol 1990; 258: H759-65

57. Yang HT, Ogilvie RW, Terjung RL Training increases collateral-dependent muscle blood flow in aged rats. $\mathrm{Am}$ J Physiol 1995; 268: H1174-80.

58. Lundgren F, Dahllöf AG, Lundholm K, Scherstén T, Volkmann R. Intermittent claudication-surgical reconstruction or physical training? A prospective randomized trial of treatment efficiency. Ann Surg 1989; 209: 346-55.

59. Hiatt WR, Regensteiner JG, Hargarten ME, Wolfel EE, Brass EP. Benefit of exercise conditioning for patients with peripheral arterial disease. Circulation 1990; 81: 602-9.

60. Johnson EC, Voyles WF, Atterbom HA, Pathak D, Sutton MF, Greene ER. Effects of exercise training on common femoral artery blood flow in patients with intermittent claudication. Circulation 1989; 80: III59-72.
61. Lundgren F, Dahllöf AG, Scherstén T, Bylund-Fellenius AC. Muscle enzyme adaptation in patients with peripheral arterial insufficiency: spontaneous adaptation, effect of different treatments and consequences on walking performance. Clin Sci (Lond) 1989; 77: 485-93.

62. Gardner AW, Katzel LI, Sorkin JD, et al. Exercise rehabilitation improves functional outcomes and peripheral circulation in patients with intermittent claudication: a randomized controlled trial. J Am Geriatr Soc 2001; 49: 755-62.

63. Brendle DC, Joseph LJ, Corretti MC, Gardner AW, Katzel LI. Effects of exercise rehabilitation on endothelial reactivity in older patients with peripheral arterial disease. Am J Cardiol 2001 1; 87: 324-9.

64. Tisi PV, Hulse M, Chulakadabba A, Gosling P, Shearman CP. Exercise training for intermittent claudication: does it adversely affect biochemical markers of the exercise-induced inflammatory response? Eur J Vasc Endovasc Surg 1997; 14: 344-50.

65. Hambrecht $\mathrm{R}$, Adams $\mathrm{V}$, Erbs $\mathrm{S}$, et al. Regular physical activity improves endothelial function in patients with coronary artery disease by increasing phosphorylation of endothelial nitric oxide synthase. Circulation 2003; 107: 3152-8.

66. Niebauer J, Maxwell AJ, Lin PS, et al. Impaired aerobic capacity in hypercholesterolemic mice: partial reversal by exercise training. Am J Physiol 1999; 276: H1346-54.

67. Lloyd PG, Yang HT, Terjung RL. Arteriogenesis and angiogenesis in rat ischemic hindlimb: role of nitric oxide. Am J Physiol Heart Circ Physiol 2001; 281: H2528-38.

68. Howald H, Hoppeler H, Claassen H, Mathieu O, Straub $\mathrm{R}$. Influences of endurance training on the ultrastructural composition of the different muscle fiber types in humans. Pflugers Arch 1985; 403: 369-76.

69. Adamopoulos S, Coats AJ, Brunotte F, et al. Physical training improves skeletal muscle metabolism in patients with chronic heart failure. J Am Coll Cardiol 1993; 21: 1101-6.

70. Hiatt WR, Regensteiner JG, Wolfel EE, Carry MR, Brass EP. Effect of exercise training on skeletal muscle histology and metabolism in peripheral arterial disease. $J$ Appl Physiol 1996; 81: 780-8.

71. Stewart KJ, Hiatt WR, Regensteiner JG, Hirsch AT. Exercise training for claudication. $N$ Engl J Med 2002; 347: 1941-51. 